\title{
Erişkin Kadınlarda Harris-Beath Yöntemi ile Elde Edilen Ayak İzlerinin Analizi: Plantar İndeksler Üzerinden Pes Planus Değerlendirmesi
}

\section{Analysis of Footprints Obtained by Harris-Beath Method in Adult Women: Evaluation of Pes Planus on Plantar Indexes}

\author{
Gizem Sakallı1 ${ }^{1}$, Serkan Özgür², Tuncay Varol ${ }^{2 *}$ \\ ${ }^{1}$ Aydın Adnan Menderes Üniversitesi Tıp Fakültesi Anatomi AD, Aydın, Türkiye. \\ ${ }^{2}$ Manisa Celal Bayar Üniversitesi Tıp Fakültesi Anatomi AD, Manisa, Türkiye. \\ e-mail: gizem.sakalli@outlook.com,serkanozg@hotmail.com, tuncay.varol@cbu.edu.tr. \\ ORCID: 0000-0003-3435-386X \\ ORCID: 0000-0002-6352-3680 \\ ORCID: 0000-0002-9857-8841 \\ *Sorumlu yazar/ Corresponding Author: Tuncay Varol \\ Gönderim Tarihi / Received: 25.03.2021 \\ Kabul Tarihi / Accepted: 13.09.2021 \\ DOI: $10.34087 /$ cbusbed. 903105
}

\begin{abstract}
Giriş ve Amaç: Ayak yapısını tanımlamak için yapılan çalışmalar, ayak içindeki anatomik yapıları ve antropometrik noktalarının ölçülmesini içerir. Harris Beath ayak izi 1stampası ayak izi elde edilmesinde sıklıkla kullanılan bir yöntemdir. Bu izlerden elde edilen veriler pes planus gibi ayak sorunlarının belirlenmesinde kullanılabilmektedir. Bu çalışmada farklı indekslerin pes planus konusunda tanı duyarlılığını ve kesme noktalarını belirlemeyi amaçladık. Gereç ve Yöntemler: Çalışmamıza 18-45 yaş aralığındaki 120 sağ lıklı yetişkin kadın katıldı. Gönüllülerin statik sağ ayak izleri Harris Beath yöntemi kullanılarak elde edildi ve bir tarayıcı yardımıyla bilgisayar ortamına aktarıldı. Görüntüler ImageJ 1.51.8 programı kullanılarak; ark indeks, Chippaux-Smiraks indeksi, Staheli indeksi ve ark açısı hesaplandı. Normal ayak ve pes planus ayırımında ark indeks $\geq 0.26$ referans kabul edildi. Nonparametrik ROC eğrisi analizi yapılarak duyarlılık, özgünlük ve kesme değerleri hesaplandı. Ölçümlere ait eğriler tanısal değeri bakımından ikili olarak karșılaștırıldı.

Bulgular: Pes planus için duyarlllık ve özgünlük değerleri; Chippoux-Smiraks indeksi için 0.86 ve 0.68 (kesme değeri: 0.374), Staheli indeksi için 0.87 ve 0.65 (kesme değeri: 0.632 ) ve ark açısı için 0.65 ve 0.78 (kesme değeri: 35,923 ) olarak bulundu. Her bir yöntem için elde edilen ROC eğrilerinin ikili karşılaştırılmasında anlamlı fark saptanmadi $(\mathrm{P}>0.05)$.

Sonuç: Ayak izinden hesaplanan Chippoux-Smiraks indeksi, Staheli indeksi ve ark açısı ölçümlerinin uygulama kolaylığı ve zararsız olması yanı sıra tanısal duyarlılık ve özgüllüklerinin yüksek olmasıyla, çalışma örnekleminin alındığı toplumda erişkin kadınlarda toplumsal pes planus taramalarında kullanılabileceği kanısındayız.
\end{abstract}

Anahtar kelimeler: Alıcı İşletim Karakteristik Eğrisi, Ayak İzi İndeksleri, Klinik Değerlendirme, Pes Planus.

\section{Abstract}

Objective: Studies conducted to define the foot structure include the anatomical structures and anthropometric points within the foot. Harris Beath footprint stamp is a frequently used method for obtaining footprints. The data obtained from these marks can be used to identify foot problems such as pes planus. In this study, we aimed to determine the diagnostic sensitivity and cut-off points of different indices in flatfoot.

Materials and Methods: 120 healthy adult women between the ages of 18-45 participated in our study. Static right footprints of the volunteers were obtained using the Harris Beath method and transferred to the computer with the help of a scanner. Images using ImageJ 1.51.8 program; arch index, Chippaux-Smiraks index, Stahel index and arch angle were calculated. In the distinction between normal foot and pes planus, arch index $\geq 0.26$ was accepted as the reference. Sensitivity, specificity and cut-off values were calculated by performing nonparametric ROC curve analysis. The curves of the measurements were compared in pairs in terms of diagnostic value. 
Results: Sensitivity and specificity values for pes planus; It was found 0.86 and 0.68 (cut-off value: 0.374 ) for the Chippoux-Smiraks index, 0.87 and 0.65 (cut-off value: 0.632) for the Staheli index, and 0.65 and 0.78 (cut-off value: 35.923 ) for the arch angle. There was no significant difference in pairwise comparison of the ROC curves obtained for each method $(\mathrm{P}>0.05)$.

Conclusion: We believe that the Chippoux-Smiraks index, Staheli index and arch angle measurements can be used in pes planus screening in adult women in the population where the study sample was taken, due to their ease of application and harmlessness, as well as their high diagnostic sensitivity and specificity.

Keywords: Clinical Assessment, Flatfoot, Footprint Index, Receiver Operating Characteristic Curve.

\section{Giriş}

Ayak, alt ekstremitenin distal kısmını oluşturup vücudun yer ile temasını sağlar. İnsan iki ayak üzerinde dik durup, yürümeye başladığında, alt ekstremitenin tümünde mekanik ve fonksiyonel bir değişim ortaya çıkmıştır. Böylelikle bu evrim sürecinde insan ayağ kavrama, insan eli de yürüme özelliğini kaybetmiştir. İnsan iki ayağı üzerinde dururken vücut ağırlığını ayak taban alanları vasıtasıyla zemine iletmektedir. Ayak yürüme, koşma ve vücudu destekleme gibi fonksiyonlarda dinamik ve statik rol oynarken, ayaktaki kasların, kemiklerin ve eklemlerin arasındaki anatomik ve fonksiyonel uyum aktivitelerin düzenini sağlamaktadır [1-4]. Ayak, eklemleri, ligamentleri, kemikleri ve kasları arasındaki karmașık bir fonksiyonel ve yapısal etkileşim yoluyla, şok emilimi, esneklik, denge ve güç gibi gereksinimleri karşılayıp zemin değişikliklerine karşı uyum sağlar $[1,5]$.

Ayakta medial longitudinal, lateral longitudinal ve transvers olmak üzere üç belirgin kavis mevcuttur. Kemik yapıların dizilişi ve kemikler arasındaki eklem ve bağlar tarafindan desteklenen kavisler, ayağa binen yükleri absorbe eden bir fonksiyona sahiptir [4]. Bu kavislerin normal yapılarını kaybetmesi durumunda yürüyüş sırasında vücut ağırlığının ayağın ön kısmına sağlıklı bir șekilde aktarılması sağlanamaz ve buna bağlı sorunların ortaya çıkmasına neden olur [6]

Ayağı daha iyi değerlendirmek için birçok yöntem geliştirilmiştir. $\mathrm{Bu}$ yöntemlerden bir tanesi ayak tabanı izinden yapılan geometrik ölçümler üzerinden geliştirilen indeksler ve açı ölçümleridir. Ayak izi ölçümleri ile yapılan değerlendirme zararsız, ucuz ve kolay olması nedeniyle ayak tabanı yapısını tanımlamakta kullanılmaktadır ve elektronik olarak alınan ayak izine göre daha güvenilirdir [7-11]. Geliştirilen çeşitli indeksler arasında ark indeks, Chippaux-Smiraks indeksi, Staheli indeksi ve ark (Clarke) açısı ölçümleri gelişimsel ayak çalışmaları, ayak patolojilerinin tanımlanması ve tarama çalışmalarında kullanılmış ve geçerlilikleri gösterilmiştir [8, 12-14].

Klinik olarak pes planus tanısında radyografik teknikler ayağın iskelet dizilimini statik ağırlık taşıma pozisyonunda değerlendirmek için altın standart olarak kabul edilir [15]. Ark indeksin radyografik tan yöntemleri ile karşılaştırıldığı çalışmalarda iyi korelasyon gösterdiği bildirilmiştir [16, 17].

Çalışmamızda ark indeksi referans kabul ederek, araştırma evrenini oluşturan sağlıklı erişkin kadınlardan alınan sağ ve sol ayak izlerinden pes planus (düz tabanlık) değerlendirmesi yapmak ve buna göre
Chippaux-Smiraks indeksi, Staheli indeksi ve ark (Clarke) açısı ölçümlerinin tanısal değerlerini belirlemek amaçlanmıştır. Her bir indeksin duyarlılık ve özgüllükleri ile kesme değerleri hesaplanarak, tanısal kesme noktalarının belirlenmesi hedeflenmiştir.

\section{Materyal ve Metot}

\subsection{Katılımcilar}

Çalışmamıza 18-45 yaş aralığında gönüllü yetişkin kadınlar katıldı. Gönüllü olan kadınlardan son 6 ayda ayak ve ayak bileğiyle ile ilgili travma geçmişi bulunmayan, anatomik bozukluğu olmayan ve daha önce alt ekstremite ile ilgili operasyon geçmişi olmayanlar çalışmaya dahil edildi. Gönüllülerden toplanan sağ ayak izleri üzerinde hesaplanan ark indekse göre 0.21 ve üzeri değere sahip olan 120 gönüllünün sağ ayak izi çalışmada kullanıldı.

Manisa Celal Bayar Üniversitesi Tıp Fakültesi Yerel Etik kurulundan çalışmayla ilgili etik kurul izni alındı. Çalışmaya katılan bireylere araştırmanın amacı ve yapılacak ölçümler hakkında sözlü olarak bilgi verildi. Katılımcılardan imzalı gönüllü onam formu alındı. Çalışma Helsinki Deklarasyonu prensiplerine uygun olarak yürütüldü.

2.2 Veri toplama araçları

2.2.1 Katılımcıların demografik verileri kaydedildi (Tablo 1).

Tablo 1. Katılımcılara ait demografik veriler; her kategori alt (min) ve üst değer (maks) aralıkları, ortalama (Ort) ve standart sapma (SS) olarak verilmiştir. (VKİ: vücut kütle indeksi)

\begin{tabular}{|l|c|c|c|}
\hline & Min-Maks & Ort & SS \\
\hline Yaş (yıl) & $18-45$ & 30.375 & 7.199 \\
\hline Boy (m) & $1.52-1.73$ & 1.622 & 0.041 \\
\hline Ăğırlı (kg) & $52.0-91.30$ & 71.002 & 8.161 \\
\hline VKI & $19.10-34.45$ & 26.942 & 3.226 \\
\hline
\end{tabular}

\subsubsection{Ayak izinin alınmast}

Katılımcı çıplak ayak ile otururken ayaklarının önüne Harris-Beath tabakası yerleştirildi. Katılımcıdan ayağa kalkıp izi alınmayacak ayağı ile tabakanın boş kısmına 
bastıktan sonra ölçüm yapılacak ayağı ile tabakanın kauçuk kısmının ortasına denk gelecek şekilde basması istendi. Birkaç saniye sabit durduktan sonra önce ölçümü gerçekleşen ayağını, sonra diğer ayağını tabakanın üzerinden çekerek geriye doğru adım atması istenerek, ayak izi alma işlemi sonlandırıldı (Resim 1).

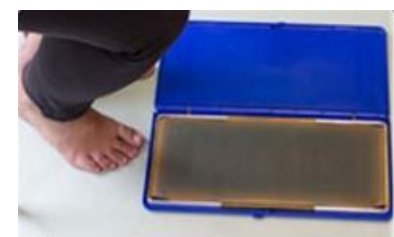

A

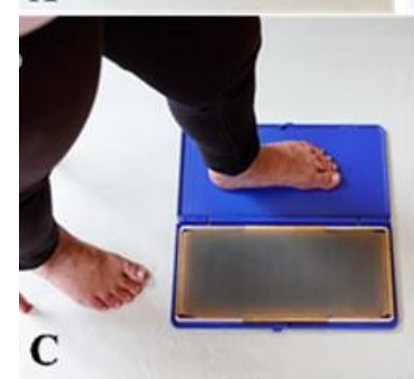

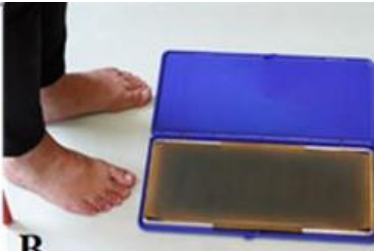

B

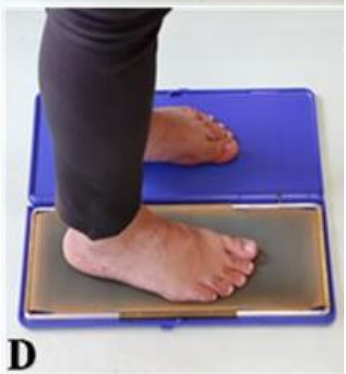

Resim 1. A) Gönüllü Harris-Beath tabakasının önünde oturur pozisyonda. B) Gönüllü tabakanın önünde ayakta dik pozisyonda. C) Gönüllünün izi alınmayacak ayağını boş kısıma bastığı pozisyon. D) Gönüllünün izi alınacak ayağını kauçuğa bastığı pozisyon.

\subsubsection{Ayak tabanı indekslerinin hesaplanmast}

Ayak taban izleri bir tarayıcı yardımıyla (Hp Scanjet 5530) bilgisayar ortamına aktarıldı. Bu görüntüler üzerinde ImageJ 1.51.8 programı kullanılarak öncelikle ark indeksi hesaplandı. Ark indeks değerleri 0.21 ve üzeri olan 120 kadının ayak izi çalışmaya dahil edildi. Ark indeksi 0.21-0.26 aralığında olanlar normal ayak (NA), 0.26'dan büyük olanlar ise pes planus (PP) olarak kabul edildi [7]. Daha sonra Chippaux-Smiraks indeksi, Staheli indeksi ve ark (ayak izi) açısı ölçümleri literatürde tanımlandığı şekilde yapıldı (Resim 2)[7, 13, $14,18]$. Tüm ölçümler aynı kişi tarafından yapıldı.

\subsubsection{Istatistiksel analiz}

Sağ ayak izlerinde ark indeks, Chippaux-Smiraks indeksi, Staheli indeksi ve ark açısı ölçümlerinden elde edilen veriler SPSS Statistics 15.0 programı kullanılarak analiz edildi. Gönüllüler ark indeksi normal değer aralığında olanlar (0.21-0.26) normal ayak (NA), 0.26 ve daha büyük olanlar pes planus (PP) olarak ikiye ayrıldı. Her bir gruba ait sağ ayak izlerinde Chippaux-Smiraks indeksi, Staheli indeksi ve ark açısı ölçümleri yapıldı. Bu ölçümlerin tanısal değerlerinin saptanması için "receiver operating characteristics" (ROC) eğrileri ve eğri altında kalan alan (EAA) hesaplandı. \%95 güven aralığında duyarlılık ve özgüllük değerleri ile Youden indeksi kullanılarak duyarlılık ve özgüllük değerlerinin toplamının en
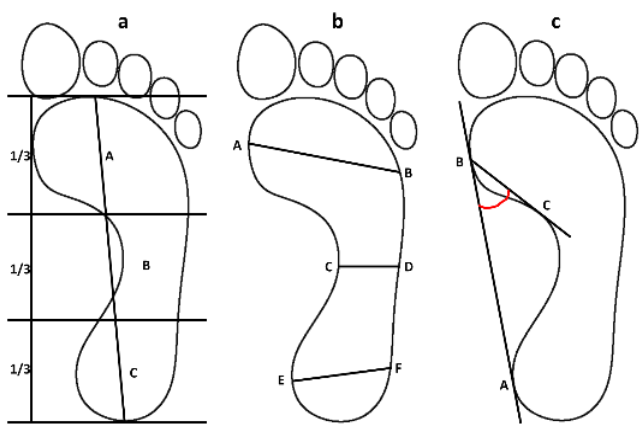

Resim 2. a) Ark indeks (AI) hesaplanırken, ayak parmakları hariç, ayak uzunluğu alınır ve 3 eşit bölüme ayrılır. Ayak orta bölgesi alanının (B) ayak parmakları hariç tüm ayak $(\mathrm{A}+\mathrm{B}+\mathrm{C})$ alanına oranı $(\mathrm{AI}=\mathrm{B} / \mathrm{A}+\mathrm{B}+\mathrm{C})$ olarak hesaplanır. b) Chippaux-Smiraks İndeksi, ayak orta bölgesininen dar mesafesinin (C-D), metatarsal alanın en geniş mesafesine (A-B) oranı (CD/AB) olarak hesaplanır. Staheli İndeksi ayak orta bölgesinin en dar mesafesinin (C-D), topuğun en geniş mesafesine (E-F) oranı (CD/EF) olarak hesaplanır. c) Ark (Clarke) açısı ayağın iç kenarına teğet geçen hat (AB) ile metatarsal bölgenin en dış noktasından (B) metatarsal bölgenin en dışı ile medial longitudinal kavsin dış hattının birleştiği nokta (C) arasındaki açıdır.

yüksek olduğu değer saptandı ve her bir ölçüm için kesme değerleri belirlendi

\section{Bulgular ve Tartışma}

\subsection{Bulgular}

Ayak izinden elde edilen indeks ve açılar Youden indeksi bakımından değerlendirildiğinde, birbirine yakın değerlerde olmakla birlikte, en yüksek Youden indeksi değerinin Chippoux-Smiraks indeksinden hesaplandığı gözlendi (Tablo 2). Eğri altında kalan alan değerleri içinde en yüksek değeri Staheli indeksi gösterirken, duyarlılık ve özgüllük bakımından en yüksek değerler sırasıyla Staheli indeksi ve ark açısında saptand 1 (Tablo 2).

Tablo 2. Sağ ayak izinden hesaplanan ark indeksi 0.26 ve daha büyük olup, pes planus olarak değerlendirilen olgularda Chippoux-Smiraks indeksi (CSI), Staheli indeksi (SI) ve ark açısı (AA) için hesaplanan Youden indeksi (YI), kesme değeri (KD) ile eğri altında kalan alan (EAA), duyarlılık, özgüllük, pozitif sonuç olasılık oranı (PSOO) ve negatif sonuç olasılık oranı (NSOO) değerleri \%95 güven aralığında (\%95 GA) verilmiştir.

\begin{tabular}{|l|c|c|c|}
\hline & $\begin{array}{c}\text { AA } \\
(\% 95 ~ G A)\end{array}$ & $\begin{array}{c}\text { CSI } \\
(\% 95 ~ G A)\end{array}$ & $\begin{array}{c}\text { SI } \\
(\% 95 ~ G A)\end{array}$ \\
\hline YI & 0.43 & 0.54 & 0.53 \\
\hline KD & 35.923 & 0.374 & 0.632 \\
\hline EAA & 0.762 & 0.803 & 0.816 \\
$(0.67-0.83)$ & $(0.72-0.87)$ & $(0.73-0.88)$ \\
\hline Duyarlılık & 65.82 & 86.08 & 87.34 \\
& $(54.3-76.1)$ & $(76.5-92.8)$ & $(78.0-93.8)$ \\
\hline Özgüllük & 78.05 & 68.29 & 65.85 \\
& $(62.4-89.4)$ & $(51.9-81.9)$ & $(49.4-79.9)$ \\
\hline PSOO & 3.0 & 2.71 & 2.56 \\
& $(1.6-5.5)$ & $(1.7-4.3)$ & $(1.7-3.9)$ \\
\hline NSOO & 0.44 & 0.20 & 0.19 \\
& $(0.3-0.6)$ & $(0.1-0.4)$ & $(0.1-0.4)$ \\
\hline
\end{tabular}


Ayak izinden elde edilen indeks ve açıların ROC analizi ile elde edilen eğri altında kalan alanları DeLong metodu ile ikili olarak karşılaştırıldığında, bu yöntemlerin pes planus değerlendirmesinde istatistiksel olarak fark göstermedikleri bulundu (Tablo 3 ).

Tablo 3. DeLong metodu kullanılarak eğri altında kalan alanların nonparametrik yöntem ile ikili karşılaştırması.

\begin{tabular}{|l|c|c|c|c|c|}
\hline & Fark & SH & $\% 95$ GA & Z & P \\
\hline CSI-SI & 0.013 & 0.023 & $\begin{array}{c}-0.031- \\
0.058\end{array}$ & 0.581 & 0.561 \\
\hline CSI-AA & 0.041 & 0.051 & $\begin{array}{c}-0.059- \\
0.143\end{array}$ & 0.801 & 0.423 \\
\hline SI-AA & 0.054 & 0.051 & $-0.045-$ & 1.071 & 0.284 \\
\hline
\end{tabular}

SH: standart hata

\subsection{Tartışma}

Ayak izi değerlendirme yöntemlerinden ark indeksi referans kabul ederek Chippoux-Smiraks indeksi, Staheli indeksi ve ark açısının pes planus yönünden tanısal değerini belirlemeyi amaçladığımız çalışmamızda, her üç yöntemin de yüksek derecede tanısal değere sahip oldukları (EAA sirasıyla 0.8030.816 ve 0.762 ) ve birbirlerine göre üstünlük bakımından anlamlı fark göstermedikleri saptand1. Her üç yöntemle de yetişkin ve sağlıklı kadınlardan alınan ayak izlerinden yapılan ölçümlerde kesme değerlerinin üzerinde kalan değerlerin pes planus öngörüsü bakımından yeterli olduğu gösterildi.

Ayak izi ölçümü kolay uygulanabilirlik ve güvenilir olmasından dolayı ayak tabanı değerlendirmelerinde sık kullanılan bir yöntemdir. Ayak tabanı ile ilgili değerlendirmelerde, ayak izi üzerinde yapılan çeşitli ölçümlerden elde edilen indeksler ve açı ölçümleri kullanılmaktadır. $\mathrm{Bu}$ yöntemler ile ayak izinin değerlendirilmesi, özellikle pes planus ve pes kavus gibi ayağın yapısal sorunlarının incelenmesinde önemlidir. Çalışmamızda da kullanılan ark indeks, Stahelli indeksi, Chippoux-Smiraks indeksi ve ark açısı pes planus ve pes kavus gibi ayak sorunlarının değerlendirilmesinde yüksek güvenirliğe sahip olduğu birçok çalışmada gösterilmiştir [19-21].

Ayak izlerini değerlendirmek için bir ölçüm yöntemi olarak kullanılan 'ark indeksi', ayağın orta bölümünün temas alanının ayağın tümünün temas alanına oranı olarak tanımlanmıştır. Cavanagh ve Rodgers ark indeksi tanımladığı çalışmada (yaş ortalamaları 30.1 olan 41'i kadın 66'sı erkek 107 birey) pes planus ve pes cavus için ayak izlerinde ölçtüğü ark indeks değerlerinin kesme noktalarını belirleyerek, bu ayak sorunlarının tanısında kullanılabilecek bir yöntem ortaya koymuşlardır. Katılımcıların Harris mat yöntemiyle elde ettikleri ayak izi görüntülerinde ark indeks ölçümünü yaparak ortalama ark indeksini $0.23 \pm 0.04$ olarak elde etmişlerdir [7]. Birçok çalışmada da ayak izlerinin değerlendirilmesinde güvenilir bir yöntem olduğu ortaya konmuştur [19, 20]. Ancak farklı toplumlarda, yaş ve cinsiyet gruplarında ve vücut ağırlığına sahip bireylerde yapılan çalışmalarda elde edilen ortalama ark indeks değerleri arasında önemli farklılıklar bulunmaktadır [20, 22, 23]. Bu durum etnik yap1, yaş, cinsiyet ve vücut ağırlığ 1 gibi faktörlerin ortalama değerleri önemli oranda etkilediğini göstermektedir. Bizim çalışmamızda çalışma evrenini oluşturan gönüllü yetişkin kadınların ortalama ark indeksi $0.28 \pm 0.04$ olarak bulunmuştur.

Cavanagh ve Rodgers yaptıkları çalışmada 0.21-0.26 arasında olan ark indeksi değerlerini normal, $\geq 0.26$ değerlerini ise pes planus olarak belirlemiştir[7]. McCrory ve arkadaşları ise ark indeks ölçümlerini radyolojik tanı yöntemi olarak naviküler yükseklik ölçümü ile karşılaştırdıkları çalışmada, her iki yöntemin iyi korelasyon $(\mathrm{r}=0.71)$ gösterdiğini ve ark indeks ölçümünün medial longitudinal kavis yükseklik değerlendirmesinde yararlı bir dolaylı ölçüm metodu olduğunu bildirmiştir [16]. Bu veriler 1şı̆̆ında çalışmamızda gönüllülerin ayak izinden elde edilen ark indeks değeri $\geq 0.26$ olanlar pes planus olarak, altındaki değerler ise normal ayak olarak kabul edilmiştir. Buna göre sağ ayak izlerinden yapılan ölçümlerde 79 ayak pes planus olarak değerlendirilmiştir.

Pes planus tanısı için ayak izlerini analiz eden üç ölçüm yönteminin geçerliliğini değerlendirmek için yapılan bir çalışmada, yaş aralığ $40-64$ olan 505 bireyin Harris mat yöntemiyle alınan ayak izlerinde ark açısı, Chippoux-Smiraks indeksi ve Staheli indeks ölçümleri yapılmış ve bu ölçümler pes planus klinik tanısı olan kişilerin ölçümleri ile karşılaştırılmıştır. Elde edilen verilerden tanısal kesme noktalarının doğruluğunu test etmek için ROC eğrisi oluşturulmuştur. Buradan optimal kesme noktasına uyan Youden Indeks değerleri, ark açısı için 0.75, Chippoux-Smiraks indeksi için 0.46, ve Staheli indeksi için 0.37 olarak, eğri altında kalan alan ise ark açısı için 0.928, Chippoux-Smiraks indeksi için 0.802 ve Staheli indeks için 0.778 olarak elde edilmiştir. Eğri altında kalan alan ve Youden indeks değerleri ark açısında daha yüksek bulunmuştur. $\mathrm{Bu}$ çalışmayı gerçekleştiren yazar tarafından pes planus taramalarında, ark açısının kullanımının daha uygun olduğu belirtilmektedir [24]. Çalışmamızda ayak izi ölçüm parametrelerinden, ark indekse göre pes planus tanısı koyduğumuz ayak izlerinde diğer indekslere göre ROC eğrisi oluşturulmuştur. Bir klinik verinin tanısal öngörü bakımından klinik etkinliğinin değerlendirilmesinde ROC eğrisi analizi kullanılmaktadır ve eğri altında kalan alan verisi kullanılmaktadır [25]. Buna göre eğri altında kalan alan ark açısı için 0.762, ChippouxSmiraks indeksi için 0.803 ve Staheli indeksi için 0.816 olarak elde edilmiştir. ROC eğrisinde özgüllük ve duyarlılık toplamının en yüksek olduğu değerden bir çıkarılarak elde edilen Youden indeks değerleri, kesme değerlerinin belirlenmesinde kullanılmıştır ve buna 
göre ark açısı için 0.43, Chippoux-Smiraks indeksi için 0.54 , ve Staheli indeksi için 0.53 olarak belirlenmiştir. Eğrinin altında kalan alan Staheli indekste, Youden indeks ise Chippoux-Smiraks indekste daha yüksek bulunmuştur.

\section{Sonuc}

Sağ ayak izinden hesaplanan ark indeksi referans alınarak normal ayak ve pes planus olarak tanımlanan gönüllülerde Chippoux-Smiraks indeksi, Staheli indeksi ve ark açısı ölçümleri yapılarak, bu yöntemlerin pes planus değerlendirmesi için yüksek tanısal değere sahip oldukları ve tarama yöntemi olarak kullanılabilecekleri değerlendirilmiştir. $\mathrm{Bu}$ testler arasında anlamlı fark olmasa da, ROC eğrisi altında kalan alan ve Youden indekslerine bakıldığında Chippoux-Smiraks indeksi ve Staheli indeksinin bizim popülasyonumuzda daha yüksek tanısal değere sahip olduklarını söyleyebiliriz.

\section{References}

1.Sammarco, G.J, Hockenbury R.T, Biomechanics of the foot and ankle. In: Nordin, M. and V.H. Frankel (ed), Basic Biomechanics of the Musculoskeletal System, $3^{\text {rd }}$ edn, Lippincott Williams \& Wilkins, New York, 2001, 222-253.

2.Drake, R, A.W, Vogl, and A.W. Mitchell, Gray's Anatomy for Students E-book, $2^{\text {nd }}$ edn, Elsevier Health Sciences, Philadelphia 2009, p.600-624.

3.Palastanga, N, Soames, R, Anatomy and Human Movement: Structure and Function, $6^{\text {th }}$ edn, Churchill Livingstone, Elsevier, Edinburgh, 2011, p.201-383.

4.Dalley II, A.F, Agur, A.M, Moore, K.L, Essential Clinical Anatomy, $5^{\text {th }}$ edn, Lippincott Williams \& Wilkins, Philadelphia, 2015, p.362-393.

5. Neumann, D.A, Kinesiology of the Musculoskeletal System; Foundation for Rehabilitation, Mosby \& Elsevier, New York, 2010, 387-472

6.Hunt, A.E, Smith, R.M, Mechanics and control of the flat versus normal foot during the stance phase of walking, Clinical Biomechanics, 2004, 19(4), 391-397.

7.Cavanagh, P.R, Rodgers, M.M, The arch index: a useful measure from footprints, Journal of Biomechanics, 1987, 20(5), p. 547-551.

8. Mathieson, I, Upton, D, Birchenough, A, Comparison of footprint parameters calculated from static and dynamic footprints, The Foot, 1999, 9(3), 145-149.

9. Urry, S.R, Wearing, S.C, A comparison of footprint indexes calculated from ink and electronic footprints, Journal of the American Podiatric Medical Association, 2001, 91(4), p. 203-209.

10. Echarri, J.J, Forriol, F, The development in footprint morphology in 1851 Congolese children from urban and rural areas, and the relationship between this and wearing shoes, Journal of Pediatric Orthopaedics B, 2003, 12(2), 141-146.

11. Goonetilleke, R.S, The Science of Footwear, CRC Press, New York, 2012, 3-112.

12. Razeghi, M, Batt, M.E, Foot type classification: a critical review of current methods, Gait \& Posture, 2002, 15(3), 282-291.

13. Stavlas, $\mathrm{P}$, et al., The evolution of foot morphology in children between 6 and 17 years of age: a cross-sectional study based on footprints in a Mediterranean population, The Journal of Foot and Ankle Surgery, 2005, 44(6), 424-428.

14. Gonzalez-Martin, C, et al., Variability between Clarke's angle and Chippaux-Smirak index for the diagnosis of flat feet, Colombia Médica, 2017, 48(1), 25.

15. Menz, H.B, Alternative techniques for the clinical assessment of foot pronation, Journal of the American Podiatric Medical Association, 1998, 88(3),119-129.

16. McCrory, J, et al., Arch index as a predictor of arch height, The Foot, 1997, 7(2), 79-81.
17. Menz, H.B, Munteanu, S.E, Validity of 3 clinical techniques for the measurement of static foot posture in older people, Journal of Orthopaedic \& Sports Physical Therapy, 2005, 35(8), 479-486.

18. Staheli, L.T, Chew, Corbett, M, The longitudinal arch. A survey of eight hundred and eighty-two feet in normal children and adults, The Journal Of Bone and Joint Surgery, American volume, 1987, 69(3), 426-428

19. Queen, R.M, et al., Describing the medial longitudinal arch using footprint indices and a clinical grading system, Foot \& Ankle International, 2007, 28(4), 456-462.

20. Fascione, J.M, Crews, R.T, Wrobel, J.S, Dynamic footprint measurement collection technique and intrarater reliability: ink mat, paper pedography, and electronic pedography, Journal of the American Podiatric Medical Association, 2012, 102(2), 130-138.

21. Zuil-Escobar, J.C, et al., Reliability and accuracy of static parameters obtained from ink and pressure platform footprints, Journal of Manipulative and Physiological Therapeutics, 2016, 39(7), 510-517.

22. Igbigbi, P.S, Msamati, B.C, Shariff, M.B, Arch index as a predictor of pes planus: a comparative study of indigenous Kenyans and Tanzanians, Journal of the American Podiatric Medical Association, 2005, 95(3), 273-276.

23. Xiong, S, et al., Foot arch characterization: a review, a new metric, and a comparison, Journal of the American Podiatric Medical Association, 2010, 100(1), 14-24.

24. Pita-Fernández, S, et al., Validity of footprint analysis to determine flatfoot using clinical diagnosis as the gold standard in a random sample aged 40 years and older. Journal of Epidemiology, 2015, 25(2), 148-154.

25. Linden, A, Measuring diagnostic and predictive accuracy in disease management: an introduction to receiver operating characteristic (ROC) analysis. Journal of Evaluation in Clinical Practice, 2006, 12(2), 132-139.

http://edergi.cbu.edu.tr/ojs/index.php/cbusbed isimli yazarın CBU-SBED başlıklı eseri bu Creative Commons Alıntı-Gayriticari4.0 Uluslararası Lisansı ile lisanslanmıştır.

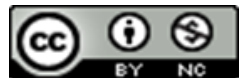

